\title{
La enseñanza de las Ciencias Sociales en Argentina y Colombia: cartografías de «antefuturo» 1
}

\author{
Ferney Quintero Ramírez² \\ Universidad Pedagógica Nacional, Bogotá, Colombia ${ }^{3}$ \\ fercho3220@hotmail.com \\ Jhon Diego Domínguez Acevedo 4 \\ Universidad Pedagógica Nacional, Bogotá, Colombia \\ jhondidoace.26@gmail.com
}

1 Artículo de Investigación grupo de investigación Educación y cultura política de la Universidad Pedagógica Nacional.

2 Estudiante de la Maestría en Educación, grupo de investigación Educación y cultura política de la Universidad Pedagógica Nacional. Licenciado en Educación Básica con Énfasis en Ciencias. Integrante del comité editorial de la Revista CEPA.

3 Grupo de investigación Educación y cultura política de la Universidad Pedagógica Nacional.

4 Estudiante de la Licenciatura en Educación Básica con Énfasis en Ciencias Sociales de la Universidad Pedagógica Nacional. Asistencia de investigación del Centro de Investigaciones Universidad Pedagógica —CIUP_. Integrante del grupo de investigación Educación y cultura política, línea de subjetividades políticas y conflicto armado. 
La enseñanza de las Ciencias Sociales en Argentina y Colombia: cartografías de «antefuturo»

\title{
Resumen
}

La enseñanza de la historia y las ciencias sociales en Latinoamérica ha estado estrechamente ligada a la investigación del campo que emergió en el decenio de 1980 - siendo más detallada la producción en aquella tendencia que en las escolares-. Por las particularidades históricas de Argentina y de otros países latinoamericanos, debido a los hechos traumáticos y las violaciones de derechos humanos que vivieron a finales del siglo pasado surgió una fuerte corriente de enseñanza de la historia reciente. Pero en Colombia las memorias de la política se han abierto campo como experiencias pedagógicas alejadas de la escuela. En tal sentido, creemos necesario pensar en unas cartografías de antefuturo - apuesta educativa - para incursionar en el presente potencial que vivimos.

Palabras clave: enseñanza de la historia, enseñanza de las ciencias sociales, memorias de la política, cartografías de antefuturo.

\section{The teaching of Social Sciences in Argentina and Colombia: cartographies of a "pre-future"}

\begin{abstract}
The teaching of history and social sciences in Latin America has been closely linked to the corresponding research that emerged in the decade of the 1980s - being more detailed the production of this tendency than the one of the school institutions' experience-- In the context of the historical particularities of Argentina and other Latin-American countries, the traumatic events and the Human Rights violations these countries experienced at the end of the last century, emerged a strong school of thought in the teaching of recent history, but in Colombia the memories of politics have emerged as pedagogical experiences cut off from school. In this sense, we think it's necessary to think of some cartographies of a "pre-future" -an educational challenge - in order to enter into the potential present in which we live.
\end{abstract}

Keywords: Teaching of history and social sciences, memories of politics, cartographies of a "pre-future", disciplinary knowledge.

\section{O ensino de Ciências Sociais na Argentina e na Colômbia: cartografias de 'pré- futuro'}

\section{Resumo}

Os ensinos de história e de ciências sociais na América Latina têm estado estreitamente unidos à investigação de campo que emergiu no decênio de 1980 - sendo mais detalhada a produção naquela tendência que nas escolas-. Pelas particularidades históricas da Argentina, e de outros países latino americanos, os fatos traumáticos e as violações de direitos humanos, que estes países viveram no final do século passado, surgiu uma forte corrente de ensino de história recente. Mas na Colômbia, as memórias da política têm aberto campo como experiências pedagógicas afastadas da escola. Em tal sentido, cremos necessário pensar em umas cartografias de pré-futuro (aposta educativa) para incursionar no presente potencial em que vivemos.

Palavras-chave: ensino de história e as ciências sociais, memórias da política, cartografias de pré-futuro. 


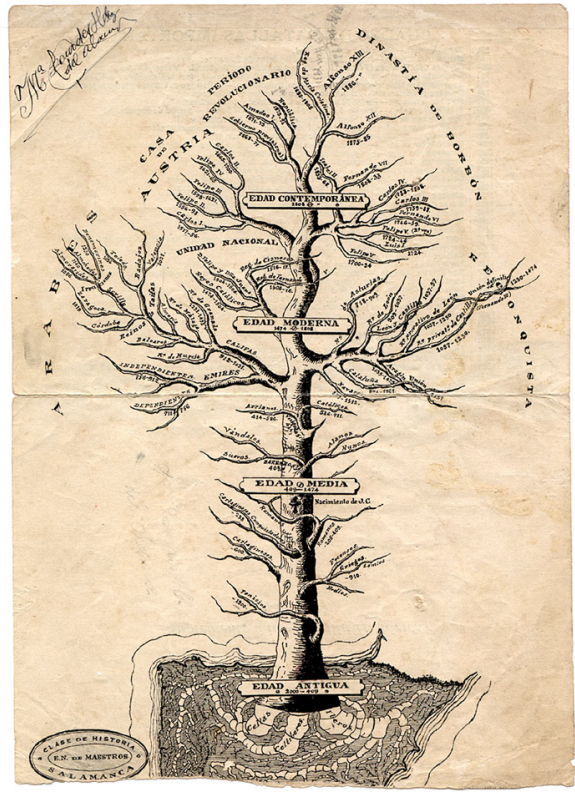

Aquí cabe preguntarse cuál puede ser el destino de esta pequeña parcela de sabiduría que les queda a los historiadores en países en los que el cambio social encuentra las resistencias más enconadas y en los que, en medio de las más extremas convulsiones sociales, los esfuerzos por comprender el cambio se señalan como una complicidad con fuerzas oscuras y desestabilizadoras.

German Colmenares Edición original en Pomares-Corredor, Barcelona, 1997 


\section{Introducción}

La enseñanza de las ciencias sociales se suele entender como la enseñanza de la historia. Tradicionalmente se asumen la historia y la geografía como las ciencias sociales escolares; la filosofía, la economía, la política aparecen como programas separados. Y ni la sociología ni la antropología surgen en el escenario escolar. Sobre el origen de la hegemonía de la historia y la geografía en la escuela como objetos enseñables y prácticas singulares debemos remitirnos a los agenciamientos de proyectos nacionales, aunque en Colombia la historia de las disciplinas escolares es un campo por explorar y está ligado a los estudios sobre los manuales escolares (Velasco Peña, 2014). La historia de las disciplinas escolares ${ }^{5}$ — que centran su lugar en el currículum - remite a preguntas por el presente: ¿de qué modo se construye hoy el currículum? ¿Cómo lo aplican los docentes «de acuerdo a determinadas circunstancias»? Pues bien, para la comprensión de dicho proceso — construcción y aplicación - es menester remontarse al pasado, el cual devela un panorama de acción educativa en un campo de investigación creciente. Así, en el decenio de 1980 se identifica una doble definición: por un lado, el currículum en su nivel preactivo es entendido no sólo como las prescripciones emanadas de órganos políticos y administrativos, sino que, además, los libros de texto de escolarización, las guías, los programas y planeaciones del profesor constituyen su fundamentación; por otro lado, la «retórica de la materia» se encuentra en su nivel interactivo, centrado en la acción curricular llevada a cabo en escenario educativo. Ambos se establecen como práctica. El primero, porque su misma construcción constituye una tradición en cuanto trazos que hacen énfasis en el requerimiento de un acto repetitivo en un determinado conjunto de prácticas. El segundo, porque la práctica en sí misma encarna la acción.

También la enseñanza de la historia, en todos los casos, debe diferenciarse del campo que ha surgido como investigaciones sobre la enseñanza de la historia, pues una cosa son los que investigan sobre cómo se ha enseñado la historia y otra muy distinta es pensar en el oficio de enseñar la historia —algunos le llaman currículo práctico-.

Los albores de los años setenta del siglo xix pueden considerarse como los inicios de la investigación contemporánea sobre enseñanza y aprendizaje de la historia en el mundo. En primer lugar, por los cambios curriculares experimentados en la enseñanza secundaria tras la Segunda Guerra Mundial. Otra razón del creciente interés por este campo de investigación ha sido la preocupación entre sus enseñantes

5 La historia de las disciplinas escolares constituye un campo de investigación configurado a partir de los años setenta, sobre todo en Gran Bretaña, por Ivor Goodson, bajo la influencia de la «nueva sociología de la educación» inglesa y de los llamados «estudios del currículum», en este caso, en el marco de la «historia cultural»y, en el ámbito de la educación, de la historia de la «cultura escolar» (Viñao, 2006). 
por la historia de la enseñanza de su disciplina o materia. Así pues, dos razones explicativas proceden, en este caso, de la misma historia de la educación como campo disciplinar: la creciente conciencia, dentro de este campo, de la necesidad de remediar el olvido del que habían sido objeto los «funcionamientos internos propios de la escuela», sus «prácticas reales» y los «resultados» obtenidos y las «capacidades realmente alcanzadas por los alumnos y su relación con los textos normativos que fija los objetivos y el programa de una determinada clase»; en otras palabras, lo que se ha denominado la «caja negra» en la historia de la educación. La última razón explica el desarrollo de la historia cultural en el ámbito de la historiografía en lo educativo. En otro sentido, es el interés por el análisis de la cultura escolar; en términos de Bourdieu (2005), el habitus —es decir, disposiciones y posiciones de un agente - implica una mirada sobre la institución escolar como espacio de producción de saber — pensar, sentir y actuar-.

A pesar de que puedan encontrarse trabajos pioneros en otras épocas, en Latinoamérica ha ocurrido un desarrollo prodigioso desde los años ochenta del siglo xx que terminó configurando un nuevo campo de saber en los escenarios universitarios. Este surgimiento guarda estrecha relación con las reformas educativas ocurridas y con la transición democrática en toda la región ${ }^{6}$.

El escenario político determinó un derrotero al campo académico emergente. Se le encomendó varias faenas: formación de la ciudadanía democrática; capacitación en competencias laborales para las nuevas condiciones de un mercado más abierto y flexible; el problema político e identitario de la memoria sobre los acontecimientos recientes; y la identificación de los procesos cognitivos particulares que se requiere para pensar históricamente (Plá \& Pagés, 2014, p. 6). Lo cierto es que surgió un campo del saber sobre el que se avocaron ingentes esfuerzos en toda la región que fue creciendo de manera local y a sus propios ritmos-que empieza a cosechar frutos en todos los terrenos, aunque principalmente en el ambiente político y cultural de Latinoamérica.

Se deben calcular las marcas que han dejado las investigaciones y avances teóricos alcanzados desde la península ibérica ${ }^{7}$ y los que han llegado allí del

6 Los sistemas educativos de Latinoamérica entraron en una profunda renovación. Se promulgaron nuevas leyes de la educación, se hicieron nuevas reformas constitucionales, se intentó cambiar los modos de gestión, se propusieron nuevos vínculos entre niveles educativos, especialmente en la primaria y secundaria, y se diseñaron innovadores planes y programas de estudio (Pla \& Pagès, 2014). Estos cambios se vieron dentro de procesos políticos y económicos más amplios como el retorno de las democracias tras criminales dictaduras, los procesos de paz al concluir desgarradoras guerras civiles o a través de transiciones menos drásticas, y la introducción regional, pero con matices nacionales, de los principios económicos de corte neoliberal.

7 La Federación Icaria —Fedicaria—, por ejemplo, en el caso español, formado por profesores de universidad, de educación secundaria y de educación primaria del ámbito de las ciencias sociales — geografía e historia- y su didáctica, se formó a partir de 1991 con el triple objetivo de elaborar 
resto de Europa. Contamos con una tradición europea que pesa sobre nuestra producción, casi que imposible de eludir. Hoy constituye una herencia que orienta el quehacer del investigador que se acerca ingenuamente a este campo. Ello se constata con vehemencia en las líneas de acción investigativa que han proliferado en Latinoamérica: aquellas que se han orientado al estudio y la producción de textos escolares o materiales para el aula; los estudios que han tratado de imprimir una «mirada interdisciplinar ${ }^{8}$ a la enseñanza de la historia; los análisis sistemáticos, comparativos, de los currículos escolares de historia en todos los países de la región y sus distancias y cercanías con el currículo ibérico; incluso la tradición crítica de la didáctica proviene de allá, aquella que forcejea por una lectura socio-histórica del currículo. Estas líneas contrastan con la enseñanza de la historia reciente, de origen latinoamericano.

Como las inclinaciones — por obvias razones - han estado centradas en la investigación sobre la enseñanza de la historia se ha olvidado intencionadamente las experiencias de enseñanza de las ciencias sociales, pues éstas requieren un trabajo sobre el terreno, es decir, allí en el escenario donde finalmente tiene lugar el acto educativo. No obstante, sí han aparecido experiencias que no se han difundido o, mejor, diluido en la maraña de producción que circula globalmente. Para el maestro de escuela son más significativas las experiencias que las investigaciones en el sentido que representan un desafío a su oficio cuando no una ayuda en contextos adversos.

Pensemos en algunas invaluables experiencias argentinas. La dictadura, la democracia y el terrorismo de Estado se han convertido en temas privilegiados de la enseñanza de la historia reciente en aquel país. Abundan las apuestas didácticas para la enseñanza de esta temática: se trabaja con testimonios, documentales, películas, artes plásticas, lectura de escritos de diversa índole (Parra, 2012); noticias y medios de comunicación (Funes y lozzia, 2012); la historia de vida (Verstraete, 2012); y el abordaje de las efemérides del 24 de marzo de 1976, fecha de instauración de la dictadura (Brizuela, 2012). No podemos dejar de dimensionar el impacto que esto tiene en la formación política de los jóvenes y niños argentinos; de igual modo, debemos pensar en Colombia pues la forma de crear una cultura de paz y democracia es forjando esos valores en la experiencia de aprendizaje en la escuela, lo que implica un cambio en la práctica docente (Domínguez \& Quintero, 2015).

materiales didácticos y desarrollar investigaciones en el campo de la didáctica de las ciencias sociales, la historia social de la escuela y el currículum y la formación del profesorado, así como un pensamiento crítico en el ámbito de la educación y la cultura (Viñao, 2006).

8 Quisiéramos defender la idea de que ningún objeto de conocimiento tiene una especificidad tal que pida la interdisciplinariedad o la transdisciplinariedad — atención: algunas situaciones o problemas, que son asuntos distintos a un objeto de conocimiento, sí requieren la concurrencia de diversos «expertos», miradas desde diferentes perspectivas...-. Lo único que la especificidad de un objeto determina es el tipo de conocimiento que puede afrontarla. 
Nuestra curiosidad, cazadora de dilemas, nos incita a discurrir por la fina línea que separa el oficio de enseñar de la impetuosa tarea de investigar con el objeto de volcar la experiencia de la enseñanza en un yacimiento de futuras investigaciones e intereses de los académicos. La escuela necesita de un maestro-investigador que tenga el potencial de difundir las experiencias ricas y complejas de su enseñanza. En tal sentido, hemos redescubierto esas increíbles invenciones y la avidez de propuestas de enseñanza de las ciencias sociales en Argentina y Colombia en dos momentos históricos bien delimitados: los ecos de la dictadura en el primero y la conmoción de los últimos procesos de paz en el segundo. En esos momentos ocurrió una posibilidad política que creó experiencias admirables, útiles a la enseñanza de la historia.

Procuraremos entablar un diálogo entre las experiencias argentinas y los experimentos de enseñanza de la historia en Colombia con el anhelo de encontrar las similitudes, las diferencias y, fundamentalmente, las rutas que ayuden a impulsar la enseñanza de la historia reciente en nuestro país. Al final, queremos arriesgar una propuesta. Por el momento, vamos tejiendo el debate.

\section{La emergencia de la enseñanza de las ciencias sociales en Argentina y Colombia}

Aunque el «boom» del campo emergente (Plá \& Pagés, 2014) de la enseñanza de las ciencias sociales ocurre en la década de 1980, esto no supone que empezó de cero pues ya había tradiciones reinantes y profundamente arraigadas en la sociedad. En otros tiempos, a la historia escolar se le encomendó una labor ejemplarizante, heroica, testimoniante y defensora de la historia de los vencedores - Conquista, Colonia, evangelización, esclavitud, nacimiento de la república, guerras, batallas, etc. - o encubridora de un pasado vergonzoso - la «Masacre de las bananeras», la «Violencia», el «Holocausto del Palacio de Justicia», el «Genocidio de la Unión Patriótica» o «la Semana Trágica», «la Década Infame», «el Cordobazo», la "Noche de los Lápices», etc.). Al maestro se le constituyó en un sujeto público, guardián de la historia patria, fuerza moral de las nuevas generaciones, productor de sentimientos patrios y de reverencia al pasado (Silva, 2013). Incluso podría hablarse de una tradición de enseñanza de la historia en la izquierda política, un cúmulo de argumentos y prácticas sustentadas en la necesidad de transformación de la sociedad con fuerte arraigo en los años sesenta y setenta del siglo xx (2013, p. 25).

Sin lugar a dudas, el pasado nacional ocupaba, con enorme importancia, la historia en la escuela latinoamericana hasta la tercera mitad del siglo xx (Amézola, 2008; Soto, 2010). Podríamos remitirnos a los sistemáticos y detallados estudios sobre los textos escolares en Argentina y Colombia para encontrar los puntos de cercanía y distancia propios de dos trayectorias tan diferenciadas pero, asimismo, tan comunes. 
Uno de los debates sustantivos que se ha sostenido en el tiempo en Colombia ${ }^{9}$ es la relación entre los textos escolares y la transposición de contenidos históricos - hasta los errores historiográficos han sido llevados a la escuela-, lo que supone la vinculación directa entre la historia escolar y el desarrollo historiográfico. Tal es el caso del Compendio de historia patria de Joaquín María Quijano, el cual se centra con prolijidad en la forma como ocurrieron los hechos en una continuación temporal, cuyo accionar pedagógico consistía en memorizar los contenidos, pues toda la historia se presenta fácilmente ordenada. La línea del tiempo era usada con exactitud y exceso pero se focalizaba en hechos políticos y militares, así como en detalles particulares, hasta irrisorios, de los héroes de la patria (Melo, 1996). De igual talante es el libro Historia de Colombia (1910), para la enseñanza secundaria, de Jesús María Henao y Gerardo Arrubla, que tuvo un predominio inaudito hasta los años setenta del siglo xx (Rodriguez Ávila, 2010). Se insistía en que para hacer realidad este proyecto de nación era necesario construir una serie de estrategias y dispositivos que permitieran impactar en la gran mayoría de la población ${ }^{10}$. Luego, cuando aparecen nuevas corrientes historiográficas y se institucionalizan los programas universitarios de formación profesional de historiadores, ocurre la transposición de los contenidos de la nueva historia. De este modo, considérese el libro que apareció en 1977, Historia de Colombia, editado por Norma, el cual forma parte de una colección de cinco títulos más ${ }^{11}$, donde se afirmaba:

El presente texto se ha concebido para ofrecer al profesorado y alumnado de primer año de enseñanza media una historia integral de Colombia tal como señala el programa oficial, analizando progresivamente los valores económicos, sociales, políticos, éticos y estéticos a través de los procesos más significativos. De este modo, abandonamos el marco tradicional que limitaba la reconstrucción del pasado colombiano a una sucesión ordenada de hechos políticos y militares en torno a biografías de caudillos y a una mitificación de personajes (Peña \& Mora, 1978).

Por lo tanto, la influencia de la historiografía sólo ha estado reducida a un cambio de contenidos en los textos escolares y no necesariamente a la transformación de las prácticas en la enseñanza de la historia. El cambio de contenidos como efecto de la

9 Según Álvarez (2007), se puede sustentar que las Ciencias Sociales escolares jugaron un papel importante en la consecución del proyecto de nación que se tenía proyectado. Éstas ayudaron a afianzar el sentimiento nacional, el valor por el pasado y los procesos identitarios. Se convirtieron, por nombrarlo de algún modo, en el instrumento que hizo extensivo a la mayoría de la población los objetivos que buscaba el Estado.

10 Este dispositivo se convierte en una de las estrategias de control dispuestas para proteger el régimen de verdad propuesto por los dirigentes políticos y eclesiásticos. Un dispositivo que exaltaba el reconocimiento del pasado español y europeo y que resultó más significativo que los referentes criollo, indígena y negro, los cuales, antes que ser recuperados para la memoria, se condenaron al olvido nacional (Pinilla, 2003).

11 Colección nuestro mundo y sus hechos: Historia de Colombia, primer grado; Historia de América; Historia del Antiguo Continente; Historia de Colombia, cuarto grado; Cátedra Bolivariana, conozcamos a Bolívar. 
renovación de tendencias historiográfica es un progreso, pero cuando no cambian las prácticas de enseñanza, ni los escenarios, ni las didácticas, ni se hace una lectura histórica de su sentido, se retorna a una eterna costumbre de enseñanza.

El desarrollo histórico de Argentina, si bien diferenciado notoriamente con el nuestro, admite algunas cercanías, se refleja claramente en los textos escolares; implica, por lo tanto, otras formas en la enseñanza de las ciencias sociales, aunque, en últimas, se reduce a manuales escolares con otros contenidos. Hay estudios detallados como los de María Balsas (2011) quien ha avanzado en análisis de problemáticas como el racismo en los textos. La autora escava en éstos buscando resquebrajar el popular mito según el cual «en la república Argentina no existen diferencias étnicas»(Balsas, 2011). Ella también ha planteado análisis sistemáticos para entender el lugar del emigrante que Ilegó a la Argentina en el siglo xx (2008), la imagen de la mujer (2014) e incluso ha incursionado en el estudio de campos como el nacionalismo, el problema obrero, la modernización, el peronismo, la dictadura y el retorno a la democracia (2009). Otras investigaciones, que se deben inventariar, son aquellas que han indagado por el «contenido ideológico» en los textos (Delia Mucsia, 2009) o sobre la propaganda política (Schlez, 2004).

Esto demuestra una producción de textos escolares más detallada debido al desarrollo de una industria editorial atenta a los cambios en las políticas educativas y curriculares, sagaces políticas de mercadeo.

Debemos ubicarnos en los inicios de la década de 1980 para entender el rudo cambio que sufre la enseñanza de las ciencias sociales en Latinoamérica ${ }^{12}$. La experiencia argentina terminó ilustrando el camino a otros paises de la región. Amézola (2008) ejemplifica cómo, a meses de retirada de los militares, sale a luz pública un libro de texto que justifica y trata con benevolencia a la junta militar y, por el contrario, construye la imagen de los guerrilleros como un grupo terrorista derrotado heroicamente por aquellos: «A partir de 1976, el movimiento guerrillero entró en una rápida declinación; el retroceso del terrorismo hizo que algunos de sus dirigentes huyeran al exterior. Posteriormente la subversión quedó duramente derrotada» (2008, p. 48). Sólo hasta unos años después con el auge del movimiento social —las familias víctimas de la dictadura y la sociedad civil— se pone en la

12 Existe a nuestro parecer dos elementos que en todos los países atraviesa la investigación en enseñanza de la historia: a) el problema político de la definición de las finalidades de la enseñanza de la historia y las ciencias sociales en la educación básica y media; b) la relación, estrecha o lejana, según el posicionamiento teórico que se sostenga, entre el saber producido por los historiadores profesionales y la enseñanza de la historia en la educación formal y la no formal, e incluso la producción de conocimiento sobre el pasado en la educación informal (Plá \& Pagès, 2014). El primero tiene que ver con los aspectos contextuales que conforman el proceso de la enseñanza de la historia; por su parte, el segundo aspecto hace referencia a la definición epistemológica de la historia, a la producción de conocimiento histórico en diferentes ámbitos y a la posibilidad de delimitar la investigación en la enseñanza de la historia y las ciencias sociales como producción científica en particular. (2014: 15). 
palestra pública la enseñanza de la historia, nace la necesidad imperiosa de enseñar la historia reciente.

\section{Nacimiento de la historia del tiempo reciente como campo de enseñanza}

En la década de 1970 se vivieron las más sangrientas dictaduras en la región latinoamericana ${ }^{13}$. En el marco de la guerra fría, la lucha contra el comunismo internacional y el auge de los movimientos sociales y políticos de izquierda revolucionaria en América Latina, Ilegaron fuertes dictaduras o Estados militares con prácticas de exterminio masivo y terror institucionalizado bajo la justificación de restablecer el orden social y político. Los procesos represivos de grandes proporciones incluyeron muertos, desaparecidos, campos de concentración, cárceles, exilios. Además:

La estrategia represiva incluyó la coordinación de acciones de las dictaduras del cono sur: el Plan Cóndor, una operación de contrainsurgencia organizada por los gobiernos de Chile, Argentina, Bolivia, Brasil, Paraguay y Uruguay, con el objeto de intercambiar información, vigilar, secuestrar y asesinar opositores de cualquiera de los países y entregarlos a los respectivos gobiernos. (Águila \& Luciani, 2008)

Las dictaduras fueron también la respuesta a la crisis del capitalismo internacional: el nuevo esquema de acumulación de capital encontró en los regímenes militares la vía para introducir en paquete las políticas neoliberales, muchas de las cuales siguieron aplicándose en la década de 1980 en medio de la transición hacia la democracia. En efecto:

Los regímenes democráticos que reemplazaron a las dictaduras no modificaron los rasgos fundamentales del modelo económico vigente y fueron los encargados de aplicar con rigor la ortodoxia neoliberal en un esfuerzo por recomponer unas economías jaqueadas por la crisis, las altísimas tasas de inflación, el estancamiento y las protestas sociales. Hacia fines de los 80 's todos los países latinoamericanos habían puesto en marcha planes de ajuste y programas de sesgo neoliberal. Si bien sólo en unos pocos países del área estas políticas económicas resultaron parcialmente exitosas, las consecuencias sociales fueron dramáticas en todos los casos, afectando la credibilidad de los regímenes democráticos que se exhibían indiferentes o impotentes frente a los reclamos sociales (Águila \& Luciani, 2008, p. 182).

Pero los problemas que presentaron las democracias latinoamericanas en los años de la transición no se quedaron en la reestructuración político-institucional o en las consecuencias económicas y sociales derivadas de la aplicación del neoliberalismo,

13 Brasil "la revolución de 1964", Chile Régimen Militar 1973-1990, Dictadura Cívico-militar de Uruguay 1973-1985, Argentina "Terrorismo de Estado" 1976-1982, Bolivia "el régimen de Banzer" (1964-1982), Paraguay Dictadura de Stroessner 1954-1989, Guatemala Dictadura de Efraín Ríos Montt 1982-1983. 
sino que hubo un profundo debate y movilización en torno a los efectos que las prácticas represivas de las dictaduras dejaron en las sociedades latinoamericanas.

El problema de la violación de los derechos humanos se configuró como una exigencia de los sectores opositores, incluso desde los últimos años de los gobiernos dictatoriales, como es el caso argentino. Los gobiernos democráticos de las décadas posteriores, por su parte, tomaron cartas en el asunto, implementaron estrategias - en su mayoría leyes de perdón, olvido, amnistías e indultos - para dar respuestas y cerrar ese tormentoso pasado para el Estado. La incapacidad de los Estados de resolver la herencia de violaciones de derechos humanos de las dictaduras explica que siga siendo un asunto de nuestra historia reciente y de las demandas políticas de la sociedad latinoamericana.

El fin de las dictaduras en Brasil, Chile y Uruguay fue muy diferente a la terminación de la dictadura argentina. En aquellas, las fuerzas armadas tuvieron la capacidad de imponer un marco jurídico-legal —Decreto ley de amnistía en Chile, Brasil, Uruguay-, que les garantizaron la ausencia de investigaciones y penalizaciones por los crímenes de lesa humanidad, e incluso mantener esferas de poder dentro del Estado después de terminada la dictadura, como es el caso chileno. Los gobiernos democráticos a pesar de reconocer la violación de derechos humanos de las dictaduras no suprimieron las leyes que garantizaban impunidad a los militares sino que las reforzaron.

Mientras, la dictadura argentina tuvo una trayectoria diferente. La derrota militar en la Guerra de las Malvinas — 1982 — de las fuerzas armadas argentinas, junto al desprestigio del gobierno como consecuencia de la crisis económica y la creciente recepción de las denuncias por la sociedad en cuanto a violaciones de derechos humanos, se impusieron sobre la incapacidad de las fuerzas armadas de mantenerse en el poder. Y con la llegada del gobierno de Raúl Alfonsín en 1983 se derogó en la primera semana de gobierno la «Ley de pacificación» que había sido expedida por el gobierno militar para garantizar su impunidad frente a la violación sistemática de los derechos humanos.

Pero las medidas del gobierno democrático que surgió en Argentina tras la caída de la dictadura tuvieron otros elementos: el juicio a las juntas militares que habían gobernado al país durante el período de 1976-1982 y a las organizaciones políticomilitares que habían actuado en el país hasta mediados del mismo periodo - por ejemplo, los montoneros—; la reforma al Código de Justicia Militar, que planteaba que a los militares involucrados en violación de derechos humanos los juzgarían tribunales civiles; la creación de la Comisión Nacional de Desaparición de Personas —CONADEP— Con el objeto de investigar los delitos cometidos entre 1976-1983, que elaboró el informe Nunca más. 
El impacto de los juicios a las juntas militares y del informe del Nunca más, que logró se condenara a los culpables, se supiera la verdad y se mantuviera abierto el proceso para nuevas condenas, incluso a oficiales de menor rango, generó una reacción de las fuerzas armadas que amenazaron con un golpe de Estado. Mientras que los familiares y organismos de derechos humanos iniciaron acciones jurídicas contra los oficiales de menor rango en la justicia civil, el gobierno de Alfonsín en diciembre de 1986 planteó la Ley de punto final que fue aprobada por el Congreso, la cual estableció un plazo límite - 30 días - para la aceptación de demandas por violación de derechos humanos y otro plazo límite —60 días — para el inicio de los juicios.

Los organismos de derechos humanos se movilizaron contra la impunidad contenida en la Ley del punto final, pero los militares tampoco se conformaron con ella y en 1987 se presentaron levantamientos militares. La nueva negociación del gobierno democrático con las fuerzas armadas concluyó con la Ley de Obediencia Debida, la cual absolvió a los oficiales de cualquier responsabilidad en los hechos de represión pasados. Las políticas estatales implementadas durante 1983-1987, no obstante, fueron progresivas en cuanto el Estado asumió las demandas de verdad y justicia sostenidas por los organismos de derechos humanos y, además, sirvieron para que la sociedad argentina conociera los delitos cometidos por las fuerzas represivas.

Pero, de otro lado, germinaron los trabajos de la memoria (Jelin, 2002) o sus luchas. El movimiento organizado y explosivo que encarnó la lucha por la memoria en Argentina inició desde los primeros años de la dictadura con la denuncia, la recopilación de información y la investigación. Florecieron las organizaciones defensoras de derechos humanos que se articularon con algunas ya existentes:

Es el caso de la Liga por los Derechos del Hombre (1937), el Servicio de Paz y Justicia (SERPA), 1974), la Asamblea Permanente por los Derechos Humanos (APDH, 1976) y el Movimiento Ecuménico por los Derechos Humanos (MEDH, 1976). Una vez iniciado el Proceso de Reorganización Nacional, a estos grupos ya existentes se sumaron nuevas organizaciones: Familiares de detenidos y desaparecidos por razones políticas (1976), Madres de Plaza de Mayo y Abuelas de Plaza de Mayo (1977), el Centro de Estudios Legales y Sociales (CELS, 1980), mientras que en el escenario democrático surgen, entre otros grupos, la Asociación de ex detenidos desaparecidos (1984), e Hijos por la Identidad y la Justicia contra el Olvido y el Silencio (HIJOS, 1996). (Ruiz, 2011).

Debe hablarse de la conformación de un universo de líneas de acción de este movimiento, con una amplia cultura organizativa, suficientemente ingeniosa para denunciar y poner en el escenario público lo que pretendía decretarse como olvido. Hábil para eludir los perseguidores con estrategias de solidaridad y apoyo comunitario. Grandes pestañeos de liderazgo. Gestión del apoyo internacional. Constantes en la investigación y en la tarea de la protesta pública. 
Con el impulso de este movimiento se contrarrestó las políticas de la memoria que procuraban configurar un tipo de memoria asociada a la condena de los crímenes de la dictadura. Una memoria que se constituyó como dominante fue la que se reflejó en el informe Nunca más. Si bien éste recogió los datos sobre la desaparición, los centros clandestinos de detención y represión, además demostró la violación sistemática de los derechos humanos e hizo central el debate en la agenda pública; también ayudó a conformar una memoria dominante que se fortaleció con las leyes de impunidad del gobierno de Alfonsín: que la dictadura era consecuencia de la existencia de grupos subversivos - formaciones guerrilleras - y que, por tanto, a ellos también le cabían los excesos y los castigos, mientras la sociedad era víctima en medio de estos dos bandos o dos demonios. Esta visión impulsada por el gobierno de Alfonsín no sólo buscó legitimar las leyes del punto final y de la obediencia debida sino propugnar la idea de perdón y olvido.

Pero esta memoria dominante fue puesta en cuestión por otras memorias. Los militares afirmaron que "lo sucedido en la Argentina había sido una "guerra", desencadenada por una "agresión subversiva" y en la cual las Fuerzas Armadas habían intervenido victoriosamente» (Águila \& Luciani, 2008). Mientras tanto, los organismos de derechos humanos, los familiares y los sobrevivientes cuestionaron la interpretación propuesta del informe del Nunca más y denunciaron la pretensión del Estado de cerrar el pasado y la deserción del mismo en la penalización de los delitos de lesa humanidad.

Durante los gobiernos «democráticos» posteriores — Menem y De la Rúa- se profundizó la política regresiva inaugurada por las leyes de impunidad. Por medio de indultos a los comandantes de las juntas militares que ya habían sido condenados y a los líderes de las organizaciones armadas que habían actuado en los setenta, se ratificó la teoría de que tanto la subversión como las juntas militares eran responsables y se les equiparó en culpas y perdones. El discurso que dominó durante ambos gobiernos fue el de la pacificación y la reconciliación. Esto igualaba a la Argentina con la situación de impunidad que predominaba en los países del Cono Sur.

Sin embargo, el rompimiento del pacto de silencio de las fuerzas armadas y la aparición de nuevos actores en el movimiento de derechos humanos, con nuevas prácticas y discursos, se instalaron con fuerza en el espacio público y social configurando un relato nuevo sobre el pasado reciente argentino. $Y$ en medio de la profunda crisis política, social y económica que vivió el pueblo argentino en las últimas décadas del siglo xx, que:

No se expresó en discursos antidemocráticos, sino en una trama ideológica y política que recorrió la sociedad argentina y que, junto con el descrédito y falta de representatividad de los partidos políticos tradicionales (el slogan fue "que se vayan todos"), [se] renovó la condena a la dictadura y sus herencias (Águila \& Luciani, 2008, p. 192). 
A pesar de que el Estado argentino mantenía las leyes de impunidad, los organismos de derechos humanos buscaron y aprovecharon herramientas jurídicas para reabrir los procesos penales a los represores: 1. Por un lado, los juicios a represores argentinos en el exterior y el impacto que generó la detención por 17 meses de Pinochet en Inglaterra a causa de la orden de arresto internacional del juez español Baltasar Garzón, tuvieron impacto en Argentina, obligando al Estado a definir su política en cuanto a la extradición de los represores y renovando el debate social y político frente al tema en el país. 2. La estrategia que emprendieron los organismos de derechos humanos, exigiendo la apertura de procesos a los represores por la apropiación de bebés nacidos en cautiverio de sus madres detenidas-desaparecidas, que no había contemplado la ley y sobre lo que había otorgado perdones a los militares.

En el 2003 el Congreso Nacional de Argentina declaró la nulidad de las leyes de impunidad, ratificado por la Corte Constitucional en el 2005, lo que contrastó con el hallazgo de restos óseos de desaparecidos. Estas medidas reabrieron casos cerrados y permitieron iniciar nuevas acciones legales, culminando en la imputación y, en contados casos, condena a los perpetradores.

Esto se dio en el marco de un nuevo gobierno democrático, el de Néstor Kirchner -2003-2007—, que al igual que con la gestión de su sucesora, permitió el surgimiento de una nueva fase de políticas de la memoria del Estado argentino:

Esta etapa, que se acompasa con los recorridos judiciales y los cambios en los discursos sociales en torno a la memoria de la dictadura, se delineó en un conjunto de medidas reparatorias que incluyeron el sacar de exhibición los cuadros de los jerarcas de la dictadura de las paredes del Colegio Militar, la expropiación y entrega del edificio de la Escuela de Mecánica de la Armada (ESMA) a organismos de derechos humanos como espacio de memoria y las disculpas ofrecidas en nombre del Estado nacional "por la vergüenza de haber callado durante veinte años de democracia por tantas atrocidades" (Águila \& Luciani, 2008, pág. 193).

En Colombia nunca hemos tenido periodos prolongados de dictadura, similares a los de las otras repúblicas latinoamericanas, pero la violencia política ha sido recurrente y el terrorismo de Estado ha sido una práctica sistemática, costosa a la sociedad colombiana. Surgieron en el país las memorias de la política, en disputa también con las políticas de la memoria. El proyecto Colombia Nunca Más nació en 1995 y hubo acercamientos a los actores de la experiencia argentina, con la participación de numerosas organizaciones no gubernamentales ${ }^{14}$, en una de

14 Iniciativa de 17 organizaciones de derechos humanos y sociales no gubernamentales en la búsqueda de recuperar la memoria de las víctimas de la última etapa de violencia política en el país: Asociación de Familiares de Detenidos Desaparecidos de Colombia —ASFADDES—, Colectivo de Abogados José Alvear Restrepo, Comisión Intercongregacional de Justicia y Paz, Fundación Comité de Solidaridad con los Presos Políticos — CSPP—, Comité Permanente por la Defensa de los Derechos Humanos 
las décadas donde la política de perpetración de crímenes de lesa humanidad fue más intensa que nunca. Esto marcó una diferencia sustancial respecto a otros países latinoamericanos, pues aquí surgió en un contexto de ejecución de políticas de terrorismo de Estado, mientras que en otros países se dio en contextos postdictatoriales, de transición a regímenes democráticos o contextos de «postguerra civil». Ello obligó a cambiar la estrategia organizativa y política pues no fue posible una «comisión de la verdad» en la década de 1990.

La Ilegada al poder de Álvaro Uribe Vélez —2002-2010_ significó la implementación de políticas de olvido e impunidad a las que las organizaciones de víctimas hicieron oposición. Por lo menos hay tres hechos que constatan esto: 1. La negación, desde su campaña política, de la existencia de un conflicto armado interno. 2. La Ley de "Justicia y Paz» — Ley 975-, que perdona a los paramilitares y pretendió darles status de grupo beligerante. 3. La idealización de las FFMM que ha llevado a crear un sentido común en el que es inadmisible que éstas tengan la mayor cuota de responsabilidad en los crímenes perpetrados contra la población civil y que, por tanto, no se les puede juzgar.

En el contexto de la ley de impunidad o desmovilización del paramilitarismo germinó el Movimiento Nacional de Víctimas de Crímenes de Estado, cuyo primer antecedente fue el I Encuentro Nacional deVíctimas de Crímenes de Lesa Humanidad y violaciones a los derechos humanos llevado a cabo los días 28 y 29 de mayo 2004. Allí participaron más de 1000 delegados, 230 organizaciones y 400 delegados regionales de 28 departamentos. Hubo acompañamiento internacional de delegados de 7 países. En el II Encuentro, al año siguiente, surgió formalmente.

El Centro Nacional de Memoria Histórica (CNMH), institución gubernamental que se impulsó desde el 2011 con la Ley de víctimas, con mayores recursos, ha impulsado el informe Basta ya, conformando una enorme producción investigativa sobre los crímenes y la violación de los derechos humanos en el país.

Asimismo, estas organizaciones han pensado la enseñanza de ese pasado tormentoso; pueden encontrarse propuestas y materiales preparados, aunque es muy corta la relación con la escuela. Una experiencia pionera es la cartilla Tejiendo memoria (2013) realizada por la Corporación Región Antioquia, basada en el informe San Carlos: memorias del éxodo en la guerra, y que cuenta con recursos

- $\mathrm{CPDH}$-, Comisión Interfranciscana de Justicia, Paz y Reverencia con la Creación, Corporación Sembrar, Comité Regional de Derechos Humanos de Santander —CREDHOS—, Fundación Reiniciar, Colectivo de Derechos Humanos Semillas de Libertad —CODEHSEL-, Corporación Jurídica Libertad, Comunidades Eclesiales de Base y Grupos Cristianos de Colombia —CEBS—, Humanidad Vigente Corporación Jurídica, Fundación Manuel Cepeda, Asociación Nacional de Usuarios Campesinos Unidad y Reconstrucción —ANUC UR_, Asociación Nacional de Ayuda Solidaria —ANDAS- y la Comunidad de los Misioneros Claretianos de Colombia. 
audiovisuales, por ejemplo, un programa radial que recoge testimonios, propuestas de recorridos pedagógicos para memorar en el territorio, describe los actores, sus estrategias y responsabilidades, plantea elementos para comprender el contexto en el que ocurrieron los crímenes y enuncia las formas de resistencia que surgieron.

Las iniciativas de memoria en las regiones y en los territorios han constituido unas experiencias prolijas pero que carecen de cercanía con la enseñanza de la historia escolar. Véase cómo las organizaciones locales han agenciado iniciativas de memoria para repoblar los territorios desolados por la guerra, refundar los territorios, rehabitar, construir nuevos imaginarios y nuevas socializaciones sobre los espacios de terror $^{15}$; iniciativas de acción colectiva que recorren y recuperan espacios comunitarios donde han ocurrido crímenes $^{16}$; construcción de espacios físicos como forma de hacer memoria ${ }^{17}$; reconstrucción de las rutas del terror para encontrar las huellas de los muertos y desaparecidos ${ }^{18}$; escenificación o representación del dolor, el sufrimiento y el sentido de ser víctimas ${ }^{19}$.

La singularidad en la historia de Argentina permitió un debate público sobre la enseñanza de la historia en el que se terminó reconociendo como objetivo primordial del currículo la enseñanza del pasado reciente. El mismo currículo y la legislación argentina permiten arriesgar la hipótesis de que éstos no fueron un producto técnico, racional, imparcial y sintetizador del conocimiento más apreciado sino que fueron resultado de diversas luchas sociales y políticas, luchas de la memoria (González, 2012). Incluso no es atrevido afirmar que la historia reciente, como campo de enseñanza, tiene una consolidación pedagógica que no ha dependido de la transposición historiográfica a la escuela. Más bien de la mano, el campo historiográfico ha surgido al detenerse en las experiencias abundantes de formación y enseñanza de las luchas por la memoria.

Con la incorporación de las «efemérides de la memoria» en 1988 se entiende el nacimiento de un nuevo currículo. Se instituyó la conmemoración del 16 de septiembre, día popularizado como «La noche de los Lápices», incluso Ilevado al cine, en el que se relata la desaparición y asesinato de estudiantes de secundaria en

15 Cineclub Itinerante La Rosa Púrpura del Cairo, un proyecto liderado por Soraya Bayuelo en la población de Carmen de Bolívar, en los Montes de María. También cabe nombrar Magdalenas por el Cauca: no más muerte por los ríos de Colombia, que consistió en una exposición-procesión liderada por el artista Gabriel Posada sobre las aguas del río Cauca en noviembre de 2008.

16 Los retornos de la Comunidad de Paz de San José de Apartadó; Peregrinaciones en Trujillo; Abriendo trochas por la vida y la reconciliación en San Luis, Antioquia.

17 Parque monumento de Trujillo; Monumento a las Víctimas de la Masacre de El Salado; Salón del Nunca Más en Granada, Antioquia; Galería Tiberio Fernández en Cali; Piedras Pintadas en San José de Apartadó; Calvarios del Oriente Antioqueño.

18 Cartografías de Fosas Comunes en San Carlos, Antioquia.

19 Performances, teatro, oralidad, plantones Las Madres de La Candelaria en Medellín y la Ruta Pacífica de las Mujeres. 
La Plata. Pero, a su vez, a las nuevas prácticas asignadas al docente se le encomendó la enseñanza de los sucesos relacionados con las dictaduras y los golpes de Estado. Pero el mayor logro estuvo en la reforma curricular de 1993 pues se logró poner de relieve y, como eje central del currículo, el período de mayor violencia y conflictividad política que atravesó Argentina en la última dictadura militar. A pesar de que los historiadores se refugiaron en el argumento de que no era un asunto que los implicara a ellos, la historia reciente entró en el currículo puesto que se reconoció su papel para la construcción de un futuro, la relevancia para la formación de ciudadanos comprometidos con la democracia. De este modo fue que se incorporó el pasado reciente en el currículo escolar de ciencias sociales.

\title{
Caja de herramientas para la enseñanza de la historia reciente
}

\author{
Simple coincidencia. Es común, en estos tiempos, \\ que se produce tanto y sobre tan diversos asuntos, \\ con autores formados en escenarios distantes pero \\ donde germinó una misma inclinación académica, se \\ produzcan contenidos parecidos de los que nadie se percata, pues, \\ ¿quién alcanza leer una producción tan exagerada?
}

Anónimo

Las luchas por la memoria en Colombia no han Ilegado a disputarse los contenidos del currículo. El escenario de paz que estamos viviendo es favorable y oportuno para disputarnos un currículo que le asigne mayor valor a nuestro pasado reciente. Pero esto contrasta, desalentadoramente, con una escuela que no está preparada para el «postacuerdo».

Se trata de un desfase o desajuste entre los cuerpos teóricos y la realidad que ocurre por la diferencia de ritmos entre la realidad y lo conceptual, es decir, los cambios conceptuales ocurren lentamente, mientras la realidad le aventaja en cambios al sujeto (Paredes, 2013); un sujeto anonadado por el ímpetu de los cambios, tratando de ajustarlos con viejos cuerpos teóricos. Y al ser un hecho verificable en toda América Latina, se trata entonces de una política sistemática de pensar sobre «realidades inventadas»: la labor de acuñar conceptos a una realidad cambiante crea realidades inexistentes.

Para salir de esta encrucijada debemos realizar una morfología de la realidad. Se trata de un programa de observación que nos lleve a la totalidad pero nos oriente hacia una nueva mirada de ésta. Labor que debe hacerse para no convertirnos en predicadores ni agentes sociales seducidos por prejuicios de una única epistemología. Se trata de buscar residencia en la incertidumbre. Crear enunciados contingentes que posibiliten descubrir los nuevos contornos de los fenómenos. Entonces la articulación brotará como una necesidad imperiosa. Y el resultado serán nuevas categorías que permitirán vivir la realidad de otro modo. 
El objetivo es ir hacia lo indeterminado de la realidad, es lograr una cartografía de antefuturo. Es una articulación dinámica, una postura, un colocarse frente al mundo, que interpela al maestro, lo convoca a ubicarse en la historia para comprender su devenir y producirla en la diversidad y multiplicidad del movimiento. La realidad histórica es emergente, es un acto de alumbramiento. Y esto implica una posibilidad ética. Crear un mundo embriagado por otros valores, otras formas de ser y estar en él. Los acontecimientos del pasado deben utilizarse para comprender y actuar sobre el presente.

Uno de las grandes tareas es superar una testaruda subjetividad del intelectual latinoamericano reinante. Se trata de una intelectualidad que no ve la realidad y afirma la derrota. Por lo tanto, es una intelectualidad en la que el discurso del poder se ontologizó. El discurso del poder es lo real. La intelectualidad se cansó rápidamente de vivir en la oposición: el sostener un pensamiento crítico es desgastante y obliga a una vida excesivamente austera. Un ejemplo más exacto son los «marxistas neoliberales» en Chile, una clara inadecuación del pensamiento con la realidad (Zemelman, 2006).

Debe surgir una epistemología del mazo. Para romper aquella comodidad se requiere un enorme mazo que retumbe y sacuda la realidad, poniendo en evidencia su flojedad, desgajándonos de ella, poniéndonos en tensión y alerta, obligándonos a inventar otra realidad. Ello implica una transformación en la forma como se nombra. Al decir de los fenomenólogos: el lenguaje es el medio donde se forman los sujetos, el lenguaje es un nido de estrategias incalculables en las relaciones de poder.

La expansión del sujeto será uno de los efectos de esta nueva epistemología del científico social. Un sujeto angustiado, pues tiene consciencia de la fragilidad de su realidad; responsable en el sentido de que pensar en él es pensar en la humanidad; asombrado, donde el conocer toma una importancia invaluable: se acercará al conocimiento como el león a su presa.

\section{Programa de la historia reciente}

Una tarea urgente es forjar espacios para difundir las experiencias de enseñanza de la historia reciente en el país y las universidades deberían tener un papel protagónico. Es necesario también crear un programa que implique a todos los que están desorientados o ignoran las potencialidades de la historia reciente. La gestión de recursos públicos será importante para crear lugares de la memoria en los colegios, para financiar recorridos pedagógicos que permitan memorar el territorio; las galerías deben llegar allí, incursionar en las nuevas tecnologías. Al maestro no puede dejársele sólo en esta labor, a él también debe preparársele para el nuevo tiempo que se está gestando. 


\section{Cartografías de antefuturo: algunos lineamientos}

\begin{tabular}{|c|c|c|c|c|}
\hline Fenómeno Época & Reciente & Frente Nacional & La Violencia & $\begin{array}{c}\text { Proyectos de Estado } \\
\text { Nación }\end{array}$ \\
\hline $\begin{array}{l}\text { Problema } \\
\text { agrario }\end{array}$ & $\begin{array}{l}\text { Despojo } \\
\text { Titulación colectiva } \\
\text { Mercado de tierras } \\
\text { Restitución }\end{array}$ & $\begin{array}{l}\text { Agricultura } \\
\text { comercial de gran } \\
\text { propiedad } \\
\text { Contrarreforma } \\
\text { Toma de tierras }\end{array}$ & $\begin{array}{l}\text { Parcelación } \\
\text { Titulación } \\
\text { Colonización } \\
\text { de frontera } \\
\text { Desalojos }\end{array}$ & $\begin{array}{l}\text { Haciendas } \\
\text { Feria de Baldíos } \\
\text { Colonización de } \\
\text { caminos } \\
\text { Ocupación }\end{array}$ \\
\hline Subversión & Guerra de guerrillas & $\begin{array}{l}\text { Guerrillas } \\
\text { comunistas }\end{array}$ & $\begin{array}{l}\text { Autodefensas } \\
\text { campesinas } \\
\text { Guerrillas } \\
\text { liberales }\end{array}$ & Ligas agrarias \\
\hline $\begin{array}{l}\text { Terrorismo de } \\
\text { Estado }\end{array}$ & $\begin{array}{l}\text { Genocidio político y } \\
\text { guerra sucia } \\
\text { Paramilitarismo } \\
\text { Guerra contra el } \\
\text { terrorismo: Plan } \\
\text { Colombia; Seguridad } \\
\text { Democrática }\end{array}$ & $\begin{array}{l}\text { Estado de Sitio: } \\
\text { Autonomía de las } \\
\text { fuerzas armadas; } \\
\text { Consejos verbales } \\
\text { de Guerra; } \\
\text { Detención } \\
\text { preventiva; } \\
\text { Desaparición } \\
\text { forzada } \\
\text { Guerra contra- } \\
\text { insurgente } \\
\text { Palacio de Justicia }\end{array}$ & $\begin{array}{l}\text { Bombardeos } \\
\text { a las regiones } \\
\text { alzadas en } \\
\text { armas } \\
\text { Guerra de } \\
\text { Villarrica } \\
\text { Asesinato } \\
\text { de líderes } \\
\text { guerrilleros } \\
\text { Asesinato de } \\
\text { estudiantes }\end{array}$ & $\begin{array}{l}\text { Represión: } \\
\text { Huelga de } \\
\text { artesanos, } 1899 \\
\text { Huelgas petroleras } \\
\text { Masacre de las } \\
\text { bananeras, } 1928\end{array}$ \\
\hline Paramilitarismo & $\begin{array}{l}\text { Las Convivir } \\
\text { Autodefensas } \\
\text { Campesinas del } \\
\text { Magdalena Medio } \\
\text { y del Noreste de } \\
\text { Antioquia } \\
\text { AUC } \\
\text { Neoparamilitarismo }\end{array}$ & $\begin{array}{l}\text { Mafia } \\
\text { Sicarios y ejércitos } \\
\text { privados } \\
\text { Leyes que } \\
\text { justificaron el } \\
\text { paramilitarismo }\end{array}$ & $\begin{array}{l}\text { Policía } \\
\text { política } \\
\text { Matones y } \\
\text { cuadrilleros: } \\
\text { Pájaros, } \\
\text { Chulavitas. }\end{array}$ & $\begin{array}{l}\text { Ideología } \\
\text { Anticomunista }\end{array}$ \\
\hline Poder político & $\begin{array}{l}\text { Descentralización } \\
\text { administrativa } \\
\text { Democratización local } \\
\text { y regional } \\
\text { Parapolítica } \\
\text { Élite neoliberal }\end{array}$ & $\begin{array}{l}\text { Guerra } \\
\text { contrainsurgente } \\
\text { Homogenización } \\
\text { política } \\
\text { Frente Nacional: } \\
\text { bipartidismo } \\
\text { Lucha armada por } \\
\text { el poder }\end{array}$ & $\begin{array}{l}\text { Frente } \\
\text { Popular } \\
\text { Emergencia } \\
\text { de la } \\
\text { izquierda } \\
\text { democrática } \\
\text { Violencia } \\
\text { política }\end{array}$ & $\begin{array}{l}\text { Bipartidismo } \\
\text { Clientelismo } \\
\text { Gamonalismo } \\
\text { Guerra civil entre } \\
\text { partidos } \\
\text { Exclusión política } \\
\text { del perdedor }\end{array}$ \\
\hline $\begin{array}{l}\text { Procesos de } \\
\text { paz }\end{array}$ & $\begin{array}{l}\text { 1990: Acuerdos con } \\
\text { el M-19 } \\
\text { 1992: Diálogos de } \\
\text { Tlaxcala } \\
\text { Diálogos del Caguán } \\
\text { Ley de Justicia y paz } \\
\text { Diálogos de la Habana }\end{array}$ & $\begin{array}{l}\text { 1984: Cese al juego, } \\
\text { tregua y paz }\end{array}$ & $\begin{array}{l}\text { Amnistías a } \\
\text { las guerrillas } \\
\text { liberales }\end{array}$ & $\begin{array}{l}\text { Amnistías } \\
\text { Pactos entre } \\
\text { partidos }\end{array}$ \\
\hline
\end{tabular}


Los acontecimientos recientes adquieren una importancia central para el historiador. Por ejemplo, el asesinato de líderes que reclaman sus tierras, que luchan porque se las restituyan, es una ventana que nos muestra el movimiento, en niveles más profundos, de una estructura agraria bimodal que se resiste a romperse. Podríamos decir lo mismo del fenómeno paramilitar, la última gran contrareforma agraria de los últimos tiempos. Son demasiado importantes los acontecimientos relacionados con el conflicto agrario y el conflicto armado interno como para dejar que sólo los interpreten los medios de comunicación. Ahí está el deber del historiador en no renunciar a este campo.

En tal sentido, el maestro será quien dirija esa interpretación del pasado en la escuela, con la obligación de develar los orígenes, las consolidaciones, las continuidades y las rupturas de los procesos históricos. 


\section{Referencias}

Águila, G., \& Luciani, L. (2008). Transición, Sociedad y Memoria en la Argentina: elementos para el análisis y perspectivas comparadas. Temas clave de historia contemporánea hoy, 177-196.

Amézola, G. (2008). Currículo oficial y memoria. El pasado reciente en la escuela argentina. Enseñanza de las ciencias sociales, 47-55.

Balsas, M. S. (2008). La imagen de los migrantes en los libros de texto para el quinto de la educación primaria. Seminario Internacional sobre Textos Escolares de Historia y Ciencias Sociales, 30.

Balsas, M. S. (2009). Los libros escolares en Argentina. Facultad Ciencias Sociales UBA, 15.

Balsas, M. S. (2011). Negritud e identidad nacional en los libros escolares argentinos: del surgimiento del sistema nacional de educación al Bicentenario. Estudios sociológicos XXIX, 86.

Brizuela, M. (2012). El abordaje de la historia reciente en el nivel primario: la efeméride del 24 de Marzo. II Jornadas Internacionales y XIV Nacionales de Enseñanza de la Historia, Rio Cuarto, Argentina, 1-15.

Delia Mucsia, A. (2009). Contenidos ideológicos de los textos escolares argentinos. Un acercamiento al análisis del discurso histórico en manuales escolares de historia. Mendoza: Universidad Nacional de Cuyo.

Funes, G., y lozzia, J. P. (2012). Noticias e Historia: un punto de articulación en el aula. III Jornadas internacionales y XIV nacionales de Enseñanza de la Historia. Rio Cuarto., 1-9.

González, M. P. (2012). Historia y memoria del pasado reciente en la escuela: una mirada a la propuesta oficial. Quinto Sol Vol. 16 No.2, 24.

Jelin, E. (2002). Los trabajos de la memoria. Buenos Aires: Siglo XXI.

Melo, J. O. (1996). Historiografía colombiana: realidades y perspectivas . Medellín: Editorial Marín Vieco.

Paredes, J. P. (2013). El Presente Potencial y la Conciencia. Realidad Social, Sujeto y Proyecto. A la memoria de Hugo Zemelman Merino. Polis No. 36, 1-13.

Parra, E. S. (2012). El uso político de la memoria y la construcción de dispositivos para pensar históricamente los sucesos traumáticos de la Argentina 1976-1983. III Jornadas Internacionales y XIV Nacionales de Enseñanza de la Historia, Rio Cuarto, Argentina., $1-15$.

Peña, M., \& Mora, C. (1978). Historia de Colombia. Editorial Norma. Colección Nuestro Mundo. Revista Colombiana de Educación No.2, 16.

Plá, S., \& Pagés, J. (2014). La investigación en enseñanza de la historia en América Latina. México D.F.: Universidad Pedagógica Nacional.

Rodriguez Ávila, S. P. (2010). Construcción de la memoria oficial en el centenario de la 
independencia: el compendio de Historia de Colombia de Henao y Arrubla. Revista Folios No. 32, 23- 42.

Ruiz, M. O. (2011). Qué y cómo recordar: luchas por la memoria en el movimiento de derechos humanos argentino (1976-1998). Nuevo mundo mundos nuevos, 30-50.

Schlez, M. (2004). Ciencia, clase y propaganda: los manuales de historia en la Argentina. Razón y Revolución No. 13, 1-9.

Silva , O. (2013). Balance historiográfico sobre la enseñanza de las ciencias sociales en Colombia. DIE, 22-42.

Soto Arango, D. (2010). La independencia americana: textos, enseñanza e imaginarios escolares en Colombia y España. Revista Historia de la Educación Latinoaméricana Vol. 14, 305-329.

Velasco Peña, G. C. (2014). La historia de la enseñanza de las ciencias sociales como referente para la transformación crítica de las prácticas educativas. Uni-pluri/versidad, Vol. 14, No.1, 78-89.

Verstraete, M. A. (2012). Vidas del pasado para forjar vidas del presente. Un método para enseñar historia. III Jornadas Internacionales y XIV nacionales de Enseñanza de la Historia. Rio Cuarto, 1-15.

Zemelman, H. (2006). Conocimiento e intelectualidad en América Latina. Su incidencia en la acción didáctica. En H. Zemelman, El conocimiento como desafío posible (págs. 21-72). México D.F.: Instituto Politécnico Nacional.

Recibido: 30 de enero de 2015

Aceptado: 31 de marzo de 2015

Cómo citar: Quintero, F. y Domínguez, J.D. (2015). La enseñanza de las Ciencias Sociales en Argentina y Colombia: cartografías de «antefuturo». Praxis Pedagógica, 17. 47-68 